\title{
Rozzano Locsin Teknolojik Yeterlilik Teorisine Göre Uzaktan Diyabet Bakımı
}

\author{
Arş. Gör. Gökşen POLAT TOPÇUOĞLU', Prof. Dr. Elif ÜNSAL AVDAL² \\ 'İzmir Tınaztepe Üniversitesi, IZMiR \\ 2izmir Kâtip Çelebi Üniversitesi, IZMir
}

\section{Derleme}

Sorumlu Yazar

Gökşen Polat Topçuoğlu

Tel: 05077841515

E-mail:

goksen.polat@tinaztepe.edu.tr

Gökşen Polat Topçuoğlu

ORCID:0000-0001-9575-2325

\section{Elif Ünsal Avdal}

ORCID:0000-0001-6888-0882

Geliş tarihi: 07.05.2021

Kabul tarihi: 05.07.2021

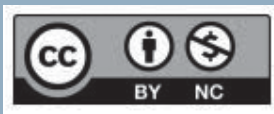

Özet

Kronik hastalıklardan biri olan diyabetin ülkemizde ve tüm dünyada görülme sıklığı giderek artmaktadır. Diyabet hastalarında kontrolsüz diyabete bağlı birçok sistemlerini etkileyen akut ve kronik komplikasyonlar oldukça sık görülmektedir. Bu nedenle tüm dünyada bulaşıcı olmayan hastalıklar arasında en önemli sağlık sorunlarından biri olarak kabul edilmektedir. Sık takip gerektiren ve doğru yönetilmediği takdirde komplikasyonlara yol açan bir hastalıktır. Gelişen teknoloji ile diyabetli bireylerin takibi ve komplikasyonlarını önlemede yeni sağlıkyaklaşımları kullanılmalıdır. Bir uygulama modeli olarak Rozzano Locsin Teknolojik Yeterlilik Teorisine Göre, hemşirelikte bakım kadar teknoloji bugün olduğu kadar gelecekte de değerli olmaya devam edecektir. Bu teori yeni sayılabilecek orta merkezli bir teoridir. Tüm bu bilgiler ışığında bu seminerde Rozzano Locsin Teknolojik Yeterlilik Teorisi'ne göre uzaktan diyabet bakım uygulamaları incelenmiştir.

Anahtar sözcükler: Telediyabet; telehemşirelik; teknoloji; hemşirelik teorisi.

\section{Abstract}

Remote Diabetes Care According to The Rozzano Locsin Technological Proficiency Theory

The prevalence of diabetes, which is one of the chronic diseases, is developing in our country and all over the world. It is seen in acute and chronic complications associated with many systems from uncontrolled diabetes. This type is considered as one of the most important health problems among non-communicable diseases all over the world. Its follow-up complex is a fully applied and correctly applicable disease. With the developing technology, complications complications and health treatments of individuals with diabetes should be used. According to Rozzano Locsin Technological Competence Theory as a practice model, technology as well as nursing care continues to be as valuable in the future as it is today. This theory is a mid-centered theory that can be considered new. In the light of all this information, remote diabetes care practices were examined in this seminar according to Rozzano Locsin Technological Sufficiency Theory.

Keywords: Telediabetes; telenursing; technology; nursing theory.

\section{Giriş}

Diyabet günümüzde giderek sayısının artmasından ve sık komplikasyon görülmesinden kaynaklı en önemli sağlık sorunlarından biri olarak kabul edilmektedir (International Diabetes Fedaration [IDF], 2019). Metabolik bir sendrom olan diyabet, sık takip gerektiren ve doğru yönetilmediği takdirde ciddi komplikasyonlara hatta ölüme yol açmaktadır. Gelişen teknoloji ile diyabetli bireylerin takibi ve komplikasyonları önlemede de yeni sağlık yaklaşımları kullanılmaktadır. Hemşirelikte teknolojilerin kullanımı, teknolojik bilgi gerektiren hemşirelik eylemlerine yönelik çağdaş taleplerin bir sonucudur (Locsin, 2009). Bu taleplerden yola çıkarak geliştirilen Rozzano Locsin Teknolojik Yeterlilik Teorisi yeni hemşirelik kuram ve modellerinden biridir. Hasta veya sağıkılı kişilerin bakımında kullanılan teknolojiler ile başa çıkabilmek, evrensel teknolojik gelişimlerin anlaşılabilmesi ve karşılanabilmesi için, "Hemşirelik Bakımında Teknolojik Yeterlilik" teorisi ile hemşirelik girişimleri yürütülebilir. Teoriye dayanan hemşirelik pratiği ile kişinin kendi hayatının anlamını yaşadığına 
dair kanıtlar, kişinin sağlık ve esenlik perspektifinden uygulandığı şekliyle hemşireliğin zenginliğini belirler (Locsin, 2005).

Bir uygulama modeli olarak, hemşirelikte bakım kadar teknolojide bugün olduğu kadar gelecekte de değerli olmaya devam edecektir. Gelişen teknolojiler doğrultusunda sağlık hizmetleri sunumunda teknolojilerden yararlanılmalıdır. Bu yararlanım içinde teknolojik yeterlilik gereklidir. Bu yeterliliğin içerisinde en önemlisi teknolojiyi bakıma nasıl aktarılacağı kısmıdır. Hemşirelikte teknolojik yeterliliğin nihai amacı, bireyi hemşireliğin bir odağı olarak kabul etmektir ve hemşirelik uygulamalarında bireyleri tanımlamada çeşitli teknolojik araçların kullanılabileceği ve kullanılması gerektiğidir (Locsin, 2010). Tüm bu bilgiler ışığında bu makalenin amacı orta merkezli, nispeten yeni olan Rozzano Locsin Teknolojik Yeterlilik Teorisi ve uzaktan diyabet bakım uygulamaları ile genel bilgi vermek ve teoriyi uzaktan diyabet bakım uygulamaları kapsamında incelemektir.

\section{Rozzano Locsin Teknolojik Yeterlilik Teorisi}

Teknolojik Yeterlilik Teorisi Rozzano Locsin tarafından geliştirilmiştir. $\mathrm{Bu}$ teoride bakım uygulamalarında hasta obje konumunda olmadan kendi bakımına aktif katılım sağlar, hemşirelerin de hastaya bakım verirken yaratıcılık, hayal gücü ve yenilikçilik becerilerinden yararlanarak, bireyi holistik yaklaşımla değerlendirip, yönetmesi gerekmektedir(Loc$\sin , 2016)$. Ayrıca bu teoriye göre her bireyin biricik olduğu buradan yola çıkarak hemşirenin hastaya özgü bakım vermesi gerektiği belirtilmiştir. Hastayı veya sağlıklı bireyi değerlendirirken hemşirelerin yararlanabileceği fakat bu durumun genellenemez olduğu vurgulanmıştır. Birey dinamik, yaşayan bir canlıdır ve elde edilen veriler de değişkendir. Değerlendirme sırasında elde edilen veriler de anlıktır. Bu nedenle genellenemez (Locsin, 2015). Bu teoride yer alan üç kavram hemşirelik sürecine dahil olarak hemşirelik uygulamalarına rehberlik eder. Bu kavramlar teknoloji bilgisi, ortaklaşa tasarım ve katılımcı etkileşimidir. Bu olaylar sıralı olabilir veya olmayabilir. Teknoloji bilgisi, sağlıkta yenilikçi yaklaşımlarından ve bakım teknolojilerinden yararlanarak bireyin sağlık veya hastalık durumlarını, bakım önceliklerini anlamanın yoludur. Teknolojiden yararlanılarak sağlanan veriler bu süreçte var olan bilgiyi destekler. Hemşire, gerçekliğe erişmek için hastanın yaşamına dahil olur ve bireyleri bakımda obje yerine koymadan bakım uygulamalarının katılımcısı olarak görür. Hemşire bireyin durumunun değişken yani anlık olduğunu, bu sürecin dinamik olduğunu unutmamalıdır. Ortaklaşa tasarım kavramı ise süreçte yer alan hemşirenin ve bakım verilen bireyin tasarımlarının beraber ele alınmasıdır (Zengin, Yıldırım, Fadıloğlu ve Aykar, 2019). Hemşirenin bakım verirken hemşirelik sürecinde bakım verdiği kişiyi tanımanın çok boyutlu bir sürecidir. Katılımcı etkileşimi ise bireyleri tanımak amacıyla önemli olan, ortaklaşa yapılacak olan etkinliklerin aynı zamanda yürütülmesini sağlar. Bu etkileşim sırasında hemşire hastanın/bireyin yaşamına girer. Böylece etkileşim sürekli olduğu zaman, farklılaşan uygulama ve değerlendirme ritmi oluşur (Locsin, 2017). Locsin teorisinde modern sağlık hizmetlerine hemşirelik uygulamalarını dahil etmek için teknoloji ile hemşirelik bakımı arasında uyumun yakalanması gerektiğini belirtmiştir. Ayrıca bire- yin hastalık durumu var olduğunda hemşirelik sürecinde bireyin takip edilmesinde ve bakımın uygulanmasında da teknolojiden yararlanarak yürütüleceğini bildirmiştir. Teknolojik Yeterlilik Teorisi hemşirelik bakımını yapılandııı. Varsayımlar, teorinin kurulduğu ve geliştirildiği felsefi ve teorik temellerin mantıksal gerçekliğini onaylar. Bu varsayımlar, hemşirelik pratiğinde hemşireye "kişileri şefkatli olarak tanımak" olarak rehberlik eden teorinin temel unsurlarını sağlar. Uygulamada gerekli olan, insan bakımı için teknolojilerin yetkin kullanımıdır(Locsin, 2017). Bu teori, hemşirelik uygulamaları sürecinde, girişimlerin verimliliğini insan bakımı perspektifinde anlaşıldığı ve takdir edildiği hükümlere izin verir. Hemşirelik uygulamasının ayrılmaz doğasını sergilemenin bir yolu olarak görülen sağlık ve esenliğin sonuçları, kişi ve hemşire arasındaki teknolojik karşılaşmalarla vurgulanmaktadır (Locsin, 2005). Rozzano Locsin Teknolojik Yeterlilik Teorisi'nin varsayımları aşağıda sıralanmıştır(Locsin ve Purnell, 2015)

- Hemşirelik bir disiplin ve profesyonel bir uygulamadır.

- Bireylere bakım verirken bireye özgü bakım verilmelidir.

- Hemşirelik uygulamasının temeli teknoloji ve hemşirelik bakımı arasında ilişki kurarak oluşturulmalıdır.

- Bireylerin sürekli bütünlüğünü değerlendirmek için teknoloji kullanılmalıdır.

\section{Uzaktan Diyabet Bakım Uygulamaları: Telediyabet}

Tele-sağlık, sağlık hizmetlerinin başka bir yere veya hastalara kurulmuş ağlar üzerinden aktarılmasıdır. Tele- tıp ise tele-sağlık hizmetlerinin klinik uygulamalarını özellikle hastaların tedavisinde ve takibinde kullanımıdır (Ertek, 2011). Iki kavram temelinde uygulanan Tele-tıp gerçek zamanlı ve eş zamansız olarak yürütülebilir. Gerçek zamanlı tele-tıp uygulamalarında her iki tarafın aynı anda katılımı gerekmektedir. Bunun yanında aralarında gerçek zamanlı bir etkileşimin gerçekleşmesine izin veren bir iletişim bağlantısına da ihtiyaç vardır. Video konferans, senkronize tele-tıpta kullanılan en yaygın teknoloji biçimlerinden biridir. Eş zamansızda ise veriler toplanır, daha sonra bu verilerin çevrimdışı değerlendirmesi uygun bir zamanda bir doktor tarafından yapılır. Burada her iki tarafın aynı anda katıımı gerekmez (Phillips, 2010). Tele-tıp gelişmiş ülkelerce kronik hastalıklarda kullanımı için desteklenmektedir. Bu hastalıklar başında diyabet gelmektedir. Uzaktan diyabet takibi ve sonuçları ile ilgili araştırmalara literatürde yer verilmiştir. Örneğin; diyabetin yakın takibi için hekimden sms, e-mail veya telefonla alınan yanıtlara göre bireylerin insülin dozları değiştirilmiş ve ayrıca bu yol ile "interaktif diyabet günlüğü" tutulmuştur (Renard, 2010). Buradaki durum özellikle insulin pompası ve sürekli glikoz monitörizasyon sistemleri (CGM) kullanan hastalarda yararlıdır (Robeznieks, 2010). Çünkü bu sistemlerin tele-tıp ile entegrasyonu kolaylıkla sağlanmaktadır. Yakın takip ile gestasyonel diyabet hastalarında doğum sırasında ve fetüste gelişebilecek komplikasyonları önleme de yararlıdır (Perez vd., 2010). Ayrıca doktora gidemeyecek durumdaki yaşlı veya gebe hastalar, sağlık imkanlarının uzanamadığı bölgelerdeki kişiler için tele-tıbbın kullanımı oldukça verimli bulunmuştur (Bonvissuto, 2010). Yaşlı gruplara sunulan tele-tıp uy- 
gulamaları bir adım öteye götürülerek akıllı ev konseptleri oluşturulmaya başlanmıştır. Bu konseptler çoğu kez aile desteğinden yoksun olan yaşlı insanların ihtiyaçlarını karşılamak amacıyla gerçekleştirilmiştir. Proje kapsamında yürütülen bu akıllı ev teknolojileri yaşlı nüfusun ağırlıkta olduğu Avustralya, Kore ve Singapur'da gerçekleştirilmiştir. Çünkü bu projenin bir amacı yaşlı diyabet hastalarının hastaneye kabul oranlarını azaltılmaya çalışılmasıdır. Tele Diyabet İzleme ve Yönetim Sisteminden yararlanılmıştır. Yöntem olarak yaşılların evinde uzaktan depolanabilen verilerle glikoz seviyeleri izlenmiştir. Bu proje sonucunda olumlu ve olumsuz durumlar bildirilmiştir. Teknoloji ile düşme, hafıza kaybı, ilaç sorunları ve sosyal izolasyona yardımcı olunmuştur. Ancak yaşlı bireylerin teknolojiyi benimseme seviyeleri düşük kalabilmektedir. Proje sonucunda tele-tıp ve akıllı evlerin yaşlıların refahını artırmak ve hastaneye yatışı azaltmak için yararlı bir yaklaşım olduğu bildirilmiştir(Phillips, 2010). Yeni tele tıp uygulama yolu daha çok Uzaktan Birincil Teşhis Ziyaretleri olarak bilinmektedir. Bu uygulamada bilgisayar tabanlı cihazlar hastayı muayene eder, başka bir yerde ikamet eden bağlantılı bir doktorun hastayı sanal olarak muayene etmesine olanak tanır ve daha sonra tedavi eder(Phillips, 2010). Telediyabet, bir tele-tıp dalıdır. Diyabete özgü uygulamalara veya cihaz kullanan diyabetlere yöneliktir. Tele tıp ilk olarak kronik diyabetik bakım için 1990'ların başında standart telefon şebekesi aracılığıyla uygulanmıştır. İlk olarak web tabanlı bir tasarıma entegre edilmiş ve uzun vadeli yönetim, hasta eğitimi ve komplikasyonların önlenmesi kavramlarına yeni bakış açıları sunmuştur. Diyabetik hastalarda uzaktan izleme sistemlerinin kullanımına ilişkin bu denemelerin sonuçları, A1c seviyesi, vücut ağırlığı ve kan şekeri gibi izlenen parametreler doğrultusunda olumlu bir etki göstermiştir(Tandon, 2009). Hastanın verilerinin aktarılmasını kolaylaştırmak için telekomünikasyon bağlantısı kurulur. Uzak lokasyonlarda ulaşılamayan diyabetli bireylerin hastalık yönetimlerini desteklemek amacıyla genellikle kullanılan bu sistemde hastanın verilerinin aktarımasını kolaylaştırmak için telekomünikasyon bağlantısı kurulur. Tele-diyabet uygulamalarında dijital oftalmoskop, dijital yağ analizörü, video konferans sistemi, elektronik stetoskop, tele-transmisyon cihazları kullanımaktadır. Tele-diyabet ile glisemik takip ve eğitimin yanında komplikasyonların takibinde de kullanılabilir. Örneğin önemli ve sık görülen sorunlardan biri olan ayak ülserlerinin takibi (Ertek, 2011) ve retinopati değerlendirmesi sistem ağları kullanarak gerçekleştirilebilir(Sanchez, Silva, Cavallerano ve Aiello, 2010). Tele-diyabet uygulamalarının hastaya ve sağlık çalışanına sağladığı birçok avantaj bulunmaktadır. Belli başlı avantajları arasında akut ve kronik komplikasyon oluşumu ve komplikasyona bağlı hastaneye yatışlarda azalma sağlaması, interaktif diyabet günlüğü tutabilme, maddi açıdan daha az kaynak ile daha fazla kişiye ulaşma ve sağlık hizmetlerine harcanan maliyeti azaltma, insülin pompası ve sürekli glukoz monitorizasyonu kullanan hastalara erişimi kolaylaştırma, hastaların demografik bilgileri ve takip kayıtlarını daha sistematik hale getirme, evde bakım hizmetlerinin iyileştirilmesi, interaktif seminerler ve video-konferanslar ile eğitime ve fikir alışverişine destek olma sayılabilir. Literatürde telediyabet ile ilgili birçok araştırma yapılmıştır. Bu araştırmalardan güncel olanlarına yer verilmiş- tir. Verhoven ve arkadaşlarının gerçekleştirdiği bir meta-analiz çalışmasında diyabet hastaları ile yapılan elektronik haberleşmenin ve video-konferansın etkinliği incelenmiş ve araştırma sonucunda bireye özgü tedavi uygulamasının maliyet-yarar açısından fayda ve sağlık hizmetinde kolaylık sağladığı bulunmuştur (Verhoeven, Tanja-Dijkstra, Nijland, Eysenbach, Van Gemert-Pijnen, 2010). Weinstock ve arkadaşlarının yaptığı bir araştırma da 1665 diyabetli birey 5 yıldan uzun süre Diyabet Eğitimi ve Tele-tıp Bilgi Ağı (IDEATel) projesi kapsamında takip edilmiş araştırma sonucunda sağlık hizmetlerine ulaşımı zor olan etnik grupların tele-tıp uygulamaları ile glisemi kontrolünde iyileşme, $\mathrm{HbA} 1 \mathrm{c}$ değerlerinde anlamlı oranlarda azalma saptanmıştır (Weinstrock vd., 2011). Aranha ve arkadaşlarının 2017 yılında'Tele Diyabetin Hasta Merkezli Sonuçları' adlı yaptıkları çalışmada ise Avustralya'nın kırsal ve uzak bölgelerinde diyabet hastalarının yönetimi için son on yıl içerisinde tele diyabet klinikleri geliştirilmiş ve çıktı olarak glikolize hemoglobin ( $\mathrm{HbA1c})$ ölçümlerindeki değişim incelenmiştir. Bireyler iki gruba ayrılmıştır. Grup 1, hastanede diyabet uzmanı tarafından rutin polikliniklerde yüz yüze görüşmelerinden, Grup 2 ise Teletıp klinikleri aracılığıyla uzaktan değerlendirilen 75 bireyden oluşmuştur. Sonuç olarak tele-diyabet uygulamalarının, Avustralya'nın uzak bölgelerinde yaşayan hastalarda diyabet tedavisinin iyileştirilmesinde uygun bir seçenek olduğuna varılmıştır (Aranha vd., 2017). Buysse ve arkadaşlarının 2020 yılında yaptıkları bir çalışmada uyarlanabilir insülin rejimli hastaların tele-tıp uygulama sonrası $\mathrm{HbA1c}$ ile sürdürülebilir iyileşme ve diyabet bakımı ile memnuniyeti tele-diyabet olarak randomize kontrollü bir şekilde 2 yıl süre ile yürütülmüştür. Tele-eğitimin glisemik kontrol ve hasta memnuniyetini iyileştirilmesine ve sürdürülmesi üzerine incelemeler yapılmıştır. Yetişkin bireyler rastgele bir şekilde çalışmaya alınmış, uzaktan eğitim veya kontrol grubuna anında erişim sağlanmış ve eğitime üç ay sonra eğitime alınmışlardır. Birkaç dakika içinde klinik veriler alınmış ve hastalardan anket doldurulması istenmiştir. Verilen tele-eğitimin glikoz ölçümleri veya hipoglisemik atak üzerine bir etkisi olmamış ancak hastalar tele-eğitimden memnun kalmışlardır(Buysse, Coremans, Pouwer ve Ruige, 2020). Guzman ve arkadaşlarının 2020 yılında yaptıkları Pediatrik Telediyabet Hizmet Modellerinin Sistematik Derlemesi'ne göre 29 çalışma incelenmiş, incelenen çalışmalara göre pediyatrik telediyabetin uzaktan izleme ve gerçek zamanlı video konferans modları ile sağlanabileceği gösterilmiştir. Pediatrik Telediyabetin hastalar ve klinisyenler arasındaki etkileşimi artırdığı, özel bakım erişimini iyileştirdiği ve diyabet takibinin artmasını kolaylaştırdığı sonucuna varılmıştır. Aynı zamanda kısa vadeli glisemik kontrolü de geliştirdiği bildirilmiştir. Engeller arasında ise hasta sorumlulukları ve klinisyenin iş yükünde artış, ekipman ve yazılımla ilgili teknik sorunlar yer almıştır (Guzman vd., 2020). Bergenstal ve arkadaşları 2021 yılında Sanal Diyabet Kliniğinde Gerçek Zamanlı Sürekli Glikoz Takibinin Tip 2 Diyabetli Yetişkinler Tarafından Uzaktan Uygulaması adlı çalışmayı yürütmüşlerdir. Tip 2 diyabetli kişiler için Onduo Sanal Diyabet Kliniği (VDC), bir mobil uygulama şeklinde geliştirilmiştir. Bu klinikte uzaktan yaşam koçluğu, diyabetli bireylerin kullandığı diyabete yönelik cihazların kontrolü ve canlı video ile konsültasyonlar gerçekleştirilmiştir. 
Örneğin bu klinikte bir endokrinolog tarafından değerlendirilen bir hastaya uzaktan gerçek zamanlı bir sürekli glikoz izleme (rtCGM) cihazı reçete edilip gönderilmiştir. Bu çalışma sonunda sensör kullanan 594 tip 2 diyabetli hastaya CGM memnuniyet anketi doldurtulmuştur. Sonuç olarak rtCGM için yüz yüze eğitim olmaksızın bir VDC aracılığıyla doğrudan bireylere eğitimin mümkün olduğu sonucuna varılmıştır (Bergenstal vd., 2021).

\section{Rozzano Locsin Teknolojik Yeterlilik}

\section{Teorisi'ne Göre Uzaktan Diyabet Bakımı}

Gelişen teknoloji ve yaşlı nüfusun artmasına bağlı olarak, kronik hastalığa sahip bireylerin sayısı ve evde bakım hizmetleri kapsamında hemşirelik hizmetlerinin sunum şeklide değişmektedir. Bu nedenle hemşireler, hasta bakımlarını ve mesleki gelişimleri için teknolojiyi takip etmelilerdir. Tele Hemşireliği, Amerikan Hemşireler Birliği (ANA) "iletişim teknolojilerinden yararlanarak hastaların sağlık durumu hakkında bilgi edinme, bakımını sağlama, hasta eğitimi gibi uygulamaları içeren hemşirelik uygulamalarıdır" şeklinde tanımlamıştır. Uluslararası Hemşireler Birliği (ICN) ise tele hemşireliği, "hasta bakımını geliştirmek için hemşirelikte iletişim teknolojilerinin kullanılmasıdır" şeklinde açıklamıştır. Rozzano Locsin Teknolojik Yeterlilik Teorisi kavramları ve varsayımları da bu tanımlamalara uymaktadır. Dünya genelinde çok yaygın görülen ve hastalık yönetiminin çok önemli olduğu kronik hastalıklardan biri olan diyabet de tele hemşireliğin, kullanılması çok önemlidir. Tele hemşireliğin aktif olarak kullanılabileceği Tele-Diyabet uygulamaları, diyabetli bireylerin yakından takip edilmesi, hekime ve hemşireye kolay erişebilmesi ile hastaların glisemik kontrol hedeflerine ulaşımını daha çok ko- kompanentler göz önüne alınarak uygulanan bu sistemin hemşirelik bakımında Rozzano Locsin Teknolojik Yeterlilik Teorisine göre işlendiği görülmektedir. Kavramsal-Teorik-Ampirik (CTE) model ile hemşirelik teorilerinin kavramsal tasvirleri yapılabilir ve hemşirelik teorileri aracılığıyla hemşirelik disiplinine yönelik ayrıntılandırılmış olan bilgilerin yönlendirmenin iyi bir yoludur (Fawcett ve Gigliotti, 2001). Kavramsal modelin kavramları ve önermeleri CT-E yapısının C'sini, araştırmacıyı ilgili literatür taramaları ve teorisi C-T-E yapısının T'sini, ve ampirik araştırma yöntemleri örneklem, araştırma tasarım, araçlar, veri toplama orta seviye teori kavramlarını C-TE yapısının E'sini oluşturmaktadır. CTE modeli çerçevesinde Rozzano Locsin Teknolojik Yeterlilik Teorisi'nin uzaktan diyabet bakım uygulamalarına yansıması şekilde verilmiştir (Şekil 1). Rozzano Locsin Teknolojik Yeterlilik Teorisi kavramlarından teknoloji bilgisi uzaktan diyabet bakım uygulamaları kapsamında ele alındığı diyabet teknolojilerinin tümü bu basamakta ele alınabilmektedir. Uzaktan bakım uygulamaları ise tele-hemşirelik kapsamında tele bakıma girmektedir. Uzaktan bakım uygulamalarına odaklanıldığında öncelikli takip gerektiren durumların başında diyabetik ayaktan korunma eğitimleri yer alabilir. Tele-diyabet ile verilen eğitimlere diyabetik ayaktan korunma uygulamaları entegre edilebilir. Web tabanlı uygulamalara diyabetik ayak bölümleri yerleştirilebilir. Diyabet günlüğü örneklerinde olduğu gibi elektronik olarak diyabetik ayak günlüğü de oluşturulabilir. Ağız ve diş sağlığı diyabet bakımlarında önemli olmasına karşın atlanabilen konulardan biridir. Teorinin bu kavramı doğrultusunda hastaların diyabet eğitimleri video yoluyla sürekli hale getirebilir. Hemşire uzaktan diyabet eğitimleri ile hastanın kendi yönetimini ve takibine bireye dahil eder. Ayrıca ev ortamına taşınan eğitimler ile hastanın yaşamına dahil olur ve bireyleri bakımda obje laylaştırabilir ve diyabet takibi için önerilen kılavuzlara da uyumunu da artırabilir. Tele diyabet ile diyet uygulamaları, kan şekeri takip izlemleri, interaktif seminerlerle hastaların diyabet eğitimlerine katılımını artııır ve doktorlar arası fikir alışverişine olanak verir. Bu yöntem ile bireyinde hastalığında alması, hastalık sorumluluğunu kabul etmesiyle, bireylere ilaç uyumu ve kontrollerinin aksatılmaması alışkanlığı kazandırılır(Ertek, 2011). Birey nesne olarak görülmez ve kendi hastalığında aktif rol alır. Tele-hemşirelikle de uzaktan diyabet uygulamaları ile birey merkezli bakım verilmiş olur. Böylece bakım verilirken teknoloji kullanımı da sağlanmış olur. Verilen eğitimler grup eğitimi olmayıp bireye özgüdür. Tüm bu

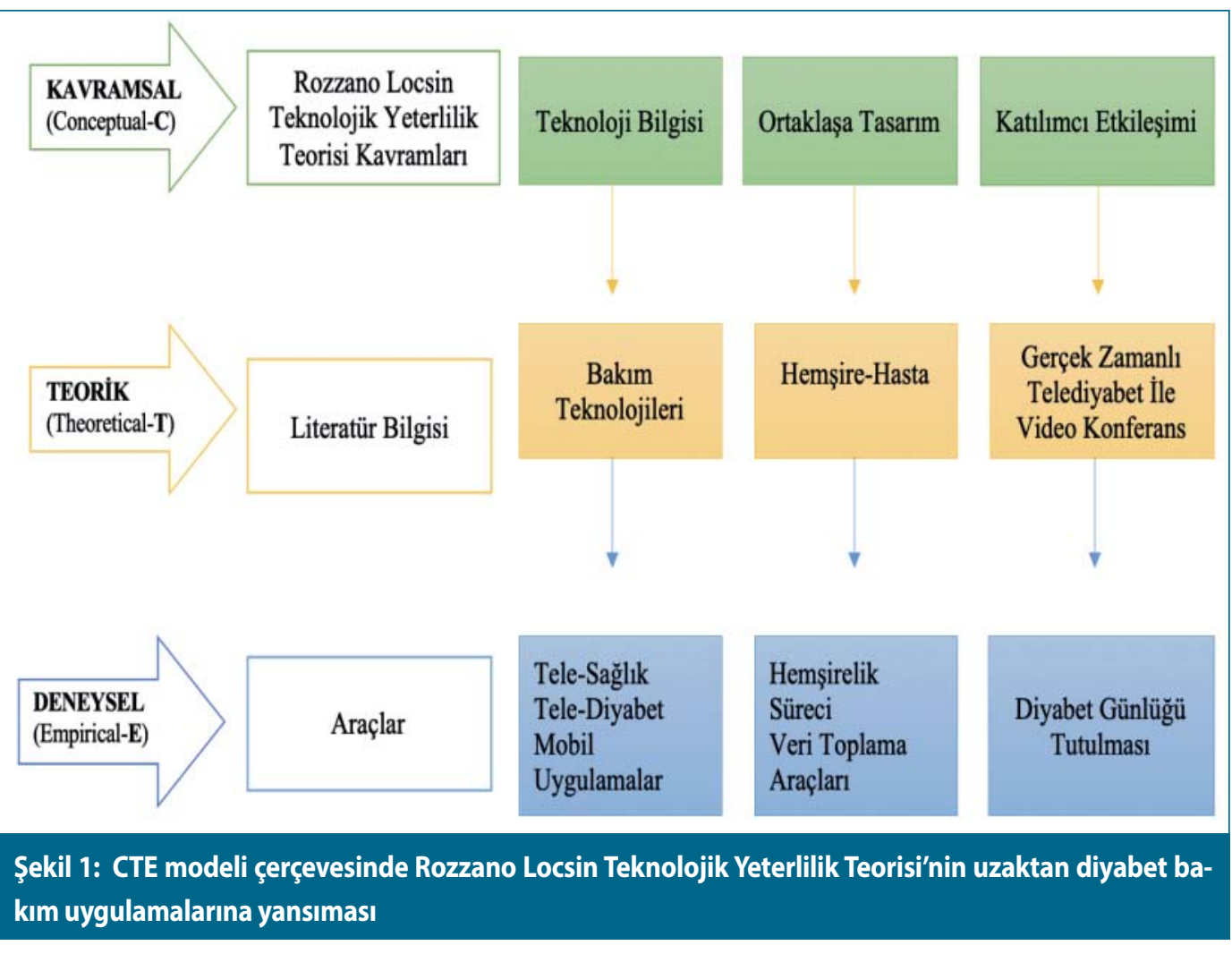


yerine koymadan bakım uygulamalarının katılımcısı olarak görür. Teoride hemşire bireyin durumunun değişken yani anlık olduğu, bu sürecin dinamik olduğu üzerinde durmuştur. Bu doğrultuda uzaktan diyabet bakım uygulamaları ile bireyin bakım uygulamalarındaki ilerlemeleri dinamik olarak takip etmiş olur. Teorinin ortaklaşa tasarım kavramına göre süreçte yer alan hemşirenin ve bakım verilen bireyin tasarımlarının beraber ele alınması gerektiği belirtilmiştir. Bakım verilen hastanın ihtiyacı olan bakıma yönelik girişimlerin verilmesi tasarım sürecini beraber ele almalarını sağlamaktadır. Bireyin eğitimini bir kez değil çoklu vermesi ile hemşirelik sürecinde bakım verdiği kişiyi çok boyutlu olarak tanıma imkanı bulur. Katılımcı etkileşimi ise bireyleri tanımak amacıyla önemli olan, ortaklaşa yapılacak olan etkinliklerin aynı zamanda yürütülmesini sağlar. Bireylerin ağız ve diş sağlığı uygulamaları diyabet eğitimleri yüz yüze verilirken zaman kısıtı olmasından kaynaklı yetersiz kalabilmektedir. Ağız mukoza takibi uzaktan hemşire tarafından tele-diyabet uygulamaları doğrultusunda yürütülebilir, diş fırçalaması istenerek uzaktan uygulamaları kontrol edilebilir.

\section{Sonuç}

Hasta sayısı ve teknolojideki yenilikler arttıkca tele-tıp ve tele-diyabet gibi uygulamaların artacağı, tıbbın geleceğinde bu sistemlerin daha da yaygın kullanılacağı açıktır. Özellikle pandemi gibi durumlarda kronik hastalığa sahip ve yakın takip gerektiren bireylerin risk ve yara ilişkisi baklımından hastaneye ziyaretlerinin azalması bu süreçleri zorunla hale getirmiştir. Bu sistemlerin yanında günümüzde mobil tele-tıp uygulamalarıda gittikçe yaygınlaşmaktadır. Tele-hemşirelik uygulamalarının tele-sağlık uygulamaları içerisine dahil olduğu görülmektedir. Ancak bakım kavramı yer aldığında tele-hemşirelik doğrultusunda tele bakım kavramınında bulunması gerekmektedir. Hemşirelik kuram ve modelleri incelendiğinde gelişen teknolojiye cevap veren Rozzano Locsin Teknolojik Yeterlilik Teorisidir. Bu teori uygulanan tüm teknolojileri kapsamaktadır. Örneğin, glukometre, insülin pompaları, CGM gibi cihazlarda bu teoride yer alan teknolojik faktörler arasında yer almaktadır. Gelişen teknoloji ve pandemi durumu dikkate alındığında sağlık sisteminde teknoloji kullanımı zorunlu bir durum haline gelmesiyle bu teoriden yararlanılarak hemşirelik bakımı verilebilir. Takibi sık gereken ve diyabet hemşireleri tarafından sürekli eğitime ihtiyacı olan grup diyabet hastalarıdır. Tele-diyabet ve tele-hemşirelik ile bireylere uzaktan diyabet bakım uygulamaları gerçekleştirilebilir. Ancak teorinin uygulanabilmesi için hemşirelerin ve hastaların teknolojik gelişimlere açık olması gerekmektedir.

\section{Kaynaklar}

1. Aranha A.A., Macdonald A., Davoren P.M., Page M., Waynforth D., Small S., Beggs J. (2017). Patient-centred outcomes of tele-diabetes. J Diabetes Treat:JDBT. DOI: 10.29011/ 2574-7568. 000026

2. Bergenstal M.R., Layne J.E., Zisser H., Gabbay R., Barleen N.A., Lee A.A., ... Dixon RF. (2021)
Remote application and use of real-time continuous glucose monitoring by adults with type 2 diabetes in a virtual diabetes clinic. Diabetes Technology and Therapeutıcs. 23(2): 128-132. DOI: 10.1089/dia.2020.0396

3. Bonvissuto K. (2010). Coming of age. Telemedicine is maturing. It can increase patient access and maybe even your income. Med Econ. 4:8714-8.

4. Buysse H., Coremans P., Pouwer F., Ruige J. (2020).Sustainable improvement of hba1c and satisfaction with diabetes care after adding telemedicine in patients on adaptable insulin regimens: Results of the telediabetes randomized controlled trial. Health Informatics Journal. 26(1): 628-641.

5. Ertek S. (2011). Endokrinolojide tele-sağlık ve tele-tıp uygulamaları. Acıbadem Üniversitesi Sağlık Bilimleri Dergisi. 2(3): 126-130.

6. Fawcett J., Gigliotti E. (2001).Using conceptual models of nursing to guide nursing research: The case of the Neuman Systems Model. Nursing Science Quarterly. 14(4): 339-345

7. Guzman K.R., Snoswell C.L., Taylor M., Senanayeke B., Haydon H.M., Batch J.A., ... Caffery L. (2020). A systematic review of pediatric telediabetes service models. Diabetes Technology and Therapeutıcs. 22(8): 623-638. DOI: 10.1089/dia.2019.0489

8. International Diabetes Federation. Diabetes Atlas Ninth Edition. (2019). https://www.diabetesatlas.org/upload/resources/material/20200302_133351_IDFATLAS9e-final-web.pdf

9. Locsin R., Purnell M. (2015). Advancing the theory of technological competency as caring in nursing: the universal technological domain. Int J Hum Caring.19:50-4.

10. Locsin R. (2005). Technological competency as caring in nursing: A model for practice. Sigma Theta Tau International Honor Society of Nursing Press. Indianapolis, IN.

11. Locsin R. (2016). Technological competency as caring in nursing: Co- creating moments in nursing occurring within the universal technological domain. The Journal of Theory Construction and Testing. 20(1): $5-11$.

12. Locsin R. (2016). The theory of technological competency as caring in nursing: Guiding nursing and health Care. Shikoku Acta Medica. 72: 5,6.

13. Locsin R., Purnell M. (2015). Advancing the theory of technological competency as caring in nursing: The universal technological domain. International Journal for Human Caring. 19 (2): $50-54$.

14. Locsin R.C. (2010). Technological competencey as caring in nursing. Smith MC, Parker ME (eds). Nursing theories and nursing practice. 3thedition. FA Davis, America. 460-470.).

15. Locsin R.C. (2017). The co-existence of technology and caring in the theory of technological competency as caring in nursing. J Med Invest. 64:160-4.

16. Pérez F.N, Galindo M., Fernández M.D., Velasco V., de la Cruz M.J., Martín P., ... Calle-Pascual AL. (2010). A telemedicine system based on internet and short message service as a new approach in the follow-up of patients with gestational diabetes. Diabetes Res Clin Pract. 87:15-17.

17. Phillips D.R. (2010). Technology and aging in the Asia-Pacific. Region. Gerontechnology. 9(2):160. doi:10.4017/gt.2010.09.02.097.00

18. Renard E. (2010). Insulin pump use in Europe. Diabetes Technol Ther. 12:29-32.

19. Robeznieks A. (2010). Long distance relationships. Telehealth use expands inconsultation education. ModHealthc. $40: 28-30$.

20. Sanchez C.R, Silva P.S, Cavallerano J.D, Aiello L.P, Ailello L.M. (2010). Ocular telemedicine for diabetic retinopathy and the joslin visoon network. Semin Ophthalmol. 25:218-24.

21. Tandon S.A. (2009). Comprehensive clinical and disease centric tele-diabetes application for the management of diabetes mellitus. Unıversıty Of Calıfornı. Master of Science Thesıs.

22. Verhoeven F., Tanja-Dijkstra K., Nijland N., Eysenbach G., van Gemert-Pijnen L. (2010). Asynchronous and synchronous teleconsultation for diabetes care: $\mathrm{A}$ systematic literature review. J Diabetes Sci Technol. 4:666-84.

23. Weinstock R.S., Teresi J.A., Goland R., Izquierdo R., Palmas W., Eimicke J.P, ... IDEATel Consortium. (2011). the IDEATel Consortium. Glycemic control and health disparities in older ethnically diverse underserved adults with diabetes: Five-year results from informatics for diabetes education and telemedicine (Ideatel) study. Diabetes Care. 34:274-9.

24. Zengin D., Yıldırım Y., Fadıloğlu Ç., Şenuzun Aykar F. (2020). Gullian-barre sendromlu çocuğun teknolojik yeterlilik teorisi doğrultusunda değerlendirilmesi. J Pediatr Emerg Intensive Care Med. 7:140-5 DOI: 10.4274/cayd.galenos.2019.52724. 